\title{
Lifetime physical activity and the risk of amyotrophic lateral sclerosis
}

\author{
Mark H B Huisman, ${ }^{1}$ Meinie Seelen, ${ }^{1}$ Sonja W de Jong, ${ }^{1}$ Kirsten R I S Dorresteijn, ${ }^{1}$ \\ Perry T C van Doormaal, ${ }^{1}$ Anneke J van der Kooi, ${ }^{2}$ Marianne de Visser, ${ }^{2}$ \\ Helenius Jurgen Schelhaas, ${ }^{3}$ Leonard $\mathrm{H}$ van den Berg, ${ }^{1}$ Jan Herman Veldink ${ }^{1}$
}

\begin{abstract}
- Additional material is published online only. To view please visit the journal online (http://dx.doi.org/10.1136/ jnnp-2012-304724).

${ }^{1}$ Department of Neurology, Rudolf Magnus Institute of Neuroscience, University Medical Centre Utrecht, Utrecht, The Netherlands ${ }^{2}$ Department of Neurology, Amsterdam Medical Centre, University of Amsterdam, Amsterdam, The Netherlands ${ }^{3}$ Department of Neurology, Donders Institute for Brain, Cognition and Behaviour, Centre for Neuroscience, Radboud University Nijmegen Medical Centre, Nijmegen, The Netherlands
\end{abstract}

\section{Correspondence to}

Dr J H Veldink, Department of Neurology, G03.228, Rudolf Magnus Institute of Neuroscience, University Medical Centre Utrecht, PO Box 85500, Utrecht 3508 GA, The Netherlands; j.h.veldink@umcutrecht.nl

MHBH, MS, LHvdB and JHV contributed equally to this work.

Received 5 December 2012 Revised 23 January 2013 Accepted 29 January 2013 Published Online First 16 February 2013

\section{ABSTRACT}

Background It has been hypothesised that physical activity is a risk factor for developing amyotrophic lateral sclerosis (ALS), fuelled by observations that professional soccer players and Gulf War veterans are at increased risk. In a population based study, we determined the relation between physical activity and risk of sporadic ALS, using an objective approach for assessing physical activity.

Methods 636 sporadic ALS patients and 2166 controls, both population based, completed a semistructured questionnaire on lifetime history of occupations, sports and hobbies. To objectively compare the energy cost of a lifetime history of occupational and leisure time physical activities and to reduce recall bias, metabolic equivalent scores were assigned to each activity based on the Compendium of Physical Activities. Results ALS patients had significantly higher levels of leisure time physical activity compared with controls (OR $1.08,95 \% \mathrm{Cl} 1.02$ to $1.14, p=0.008$ ). No significant difference was found between patients and controls in the level of vigorous physical activities, including marathons and triathlons, or in occupational activity. Cumulative measures of physical activity in quartiles did not show a dose-response relationship.

Conclusions An increased risk of ALS with higher levels of leisure time physical activity was found in the present study. The lack of association with occupational physical activity and the absence of a dose-response relationship strengthen the hypothesis that not increased physical activity per se but rather a genetic profile or lifestyle promoting physical fitness increases ALS susceptibility.

\section{INTRODUCTION}

Sporadic amyotrophic lateral sclerosis (ALS) is believed to be a complex disease, with multiple genetic and environmental factors causing motor neuron degeneration. ${ }^{1}$ Ever since Lou Gehrig, the legendary 1930s baseball player known as 'The Iron Horse', died from ALS, it has been hypothesised that physical activity is a risk factor for developing this disease. Although assuming an association based on an individual well known patient is fraught with risk, the hypothesis has been fuelled by recent observations that professional soccer and football players, and Gulf War veterans, are at increased risk of sporadic ALS. ${ }^{2-6}$ Several theories have been proposed that may explain the possible association of physical activity with ALS susceptibility. $^{7-9}$

Although some studies have suggested a relation between physical activity and the risk of ALS, the results may have been biased due to methodological shortcomings inherent in studying a relatively low incidence disease. ${ }^{3}{ }^{10-13}$ A population based case control study can alleviate some of these limitations and, therefore, provide a high level of evidence in ALS exogenous risk factor studies.

We performed a large population based case control study in The Netherlands to determine the relation between physical activity and the risk of sporadic ALS, adjusted for known risk factors, using an objective quantitative approach for assessing physical activity, and taking into account the lifetime history of occupational and leisure time activities of each patient and control. To minimise recall bias, we measured the energy cost of the lifetime history of occupational and leisure time physical activities in an objective manner by assigning metabolic equivalent (MET) scores to each activity based on the Compendium of Physical Activities. ${ }^{14}$

\section{METHODS}

\section{Study population}

The Prospective ALS study The Netherlands (PAN) is a population based case control study performed in The Netherlands during the period 1 January 2006 to 31 December 2010. Complete case ascertainment was ensured by continuous recruitment through multiple sources: neurologists, rehabilitation physicians, the Dutch Neuromuscular Patient Association and our ALS website.

All patients diagnosed with possible, probable (laboratory supported) or definite ALS according to the revised El Escorial criteria were included. ${ }^{15}$ Medical records were scrutinised for eligibility of patients, excluding patients with an ALS mimic syndrome or with a first, second or third degree family member with ALS. As exogenous factorsprobably-had only a minor role in the development of ALS in patients with the highly penetrant C9ORF72 repeat expansion, these patients, 43 in total, were excluded from our analysis. ${ }^{16-18}$

To ascertain population based controls, the general practitioner of the participating patient was asked to select individuals from his register in alphabetical order starting at the surname of the patient. The Dutch health care system ensures that every inhabitant is registered with a general 
practitioner, which makes this roster representative of the population. Controls were matched to patients for gender and age ( \pm 5 years). This study, however, did not use individual matching, meaning that some general practitioners delivered several controls while others delivered none. As can be seen in table 1, our case and control groups were well matched for age and gender. Blood relatives or spouses of patients were not eligible to be controls, to prevent over matching.

Ethics approval was provided by the institutional review board of the University Medical Centre Utrecht. All participants gave written informed consent.

\section{Data collection}

A structured questionnaire was used to collect demographic and clinical characteristics of participants and to obtain data regarding lifetime physical activities. Participants were asked to recollect all of their jobs and to describe the various activities they had to perform during these jobs. They were also asked to list all of their leisure time activities, consisting of sports and hobbies. For each activity, the participant was asked to state the number of years and how many hours per week the activity was performed. Specific questions were asked about vigorous physical activities (eg, marathon, triathlon, etc). This questionnaire was part of a larger questionnaire containing questions on several other exogenous factors. Participants were, therefore, blinded to the hypothesis being tested. In the patient group,

Table 1 Baseline demographic and clinical characteristics of participants

\begin{tabular}{|c|c|c|c|}
\hline Characteristic & $\begin{array}{l}\text { ALS patients } \\
(n=636)\end{array}$ & $\begin{array}{l}\text { Controls } \\
(n=2166)\end{array}$ & $\mathrm{p}$ Value \\
\hline Male (n (\%)) & $395(62.1)$ & $1259(58.1)$ & 0.17 \\
\hline $\begin{array}{l}\text { Age (years) (median } \\
(\text { range) })^{*}\end{array}$ & 63 (23 to 87 ) & 62 (20 to 91$)$ & 0.91 \\
\hline \multicolumn{4}{|l|}{ Site of onset (n (\%)) } \\
\hline Bulbar & $204(32.3)$ & & \\
\hline Spinal & $427(67.7)$ & & \\
\hline \multicolumn{4}{|l|}{$\begin{array}{l}\text { El Escorial classification ( } \mathrm{n} \\
(\%) \text { ) }\end{array}$} \\
\hline Definite & $112(17.8)$ & & \\
\hline Probable & $280(44.6)$ & & \\
\hline Probable lab supported & $111(17.7)$ & & \\
\hline Possible & $119(18.9)$ & & \\
\hline \multicolumn{4}{|l|}{ Education (n (\%)) } \\
\hline No education & $2(0.3)$ & $3(0.1)$ & \\
\hline Primary school & $54(8.5)$ & $131(6.1)$ & \\
\hline $\begin{array}{l}\text { Junior vocational } \\
\text { education }\end{array}$ & $127(20.0)$ & $356(16.5)$ & \\
\hline $\begin{array}{l}\text { Lower general } \\
\text { secondary education }\end{array}$ & $149(23.4)$ & $474(21.9)$ & 0.02 \\
\hline $\begin{array}{l}\text { Intermediate vocational } \\
\text { education }\end{array}$ & $106(16.7)$ & $410(18.9)$ & \\
\hline $\begin{array}{l}\text { Higher general } \\
\text { secondary education }\end{array}$ & $45(7.1)$ & $186(8.6)$ & \\
\hline College/university & $153(24.1)$ & $604(27.9)$ & \\
\hline $\begin{array}{l}\text { BMI }\left(\mathrm{kg} / \mathrm{m}^{2}\right) \text { (median } \\
\text { (range)) }\end{array}$ & 24.1 (12 to 48$)$ & 25.6 (16 to 53$)$ & $<0.001$ \\
\hline Current smoking (n (\%)) & $133(20.9)$ & $288(13.3)$ & $<0.001$ \\
\hline $\begin{array}{l}\text { Current alcohol } \\
\text { consumption (n (\%)) }\end{array}$ & $475(74.7)$ & $1846(85.3)$ & $<0.001$ \\
\hline
\end{tabular}

only data referring to the period before disease onset were analysed. Survival status of the patients was recorded up to 8 August 2011 and obtained through the municipal personal records database or from the general practitioner. If the questionnaire was not completed in full or if data were found to be inconsistent, participants were approached by telephone to complete or correct the data. To ensure blinding, all questionnaires were coded prior to processing and analysis.

\section{Classification of physical activities}

To objectively quantify the cumulative lifetime physical activity level of participants, all reported activities were scored and coded based on the Compendium of Physical Activities. ${ }^{14}$ The Compendium provides a coding scheme that links specific activities performed in various settings with their respective MET. The definition of an MET is the ratio of work metabolic rate to a standard resting metabolic rate. A MET score of 1.0 (ie, the standard or resting metabolic rate while sitting quietly) is defined as $1 \mathrm{kcal} \times \mathrm{kg}^{-1}$ body weight $\times \mathrm{h}^{-1}$. MET levels for specific activities, as reported in the Compendium, were established by reviewing published and unpublished studies that measured the energy cost of human physical activities. The compendium describes 605 specific activities. Assignment of MET scores to the activities enabled us to calculate cumulative scores of all reported physical activities:

$$
\sum_{\mathrm{k}=1}^{\mathrm{n}}\left(\text { MET } \text { score }_{\mathrm{k}} \times \text { duration in year } \mathrm{k}_{\mathrm{k}} \times \text { hours per week } \mathrm{k}_{\mathrm{k}}\right)
$$

where $\mathrm{k}$ represents an activity from the lifetime job or leisure time history. Because of the magnitude of the cumulative score, it was divided by 1000 . Activities that had a MET score of $\leq 1.5$ (eg, listening to music, reading, playing chess, needlework) were not included in the analysis. Subsequently, military service (not occupation) or periods spent as a homemaker were excluded because of difficulties quantifying these activities. Military service was mandatory for male study participants during a 15-24 month period around the age of 18 years and will therefore have minimal influence on total cumulative physical activity. In our study, $34 \%$ of patients compared with $35 \%$ of controls joined the military service $\left(\chi^{2}\right.$ test: $\left.p=0.73\right)$, and $12 \%$ of both patients and controls reported periods spent as a homemaker $\left(\chi^{2}\right.$ test: $\left.p=0.77\right)$.

\section{Statistical methods}

Univariate and multivariate logistic regression were used to determine the association of physical activity and the risk of ALS. Standard unconditional logistic regression was used as the study did not include individual case control pairs but was frequency matched. The risk of ALS with cumulative scores of physical activity was analysed separately for leisure time activity, occupational activity and total activity (the combined leisure time and occupational activity) as a continuous variable. Furthermore, to determine a dose-response relationship, physical activity was categorised into quartiles based on the data of controls. The first quartile with the lowest intensity in physical activities was defined as the reference category. Multivariate logistic regression was used to determine the association between the four levels of physical activity and ALS. A separate multivariate logistic regression analysis was performed to determine the effect of vigorous physical activity (ever/never) on the risk of ALS. OR and $\mathrm{p}$ values were derived from these analyses. In the multivariate model, the ORs were adjusted for gender, 
age (at onset for patients and at the date the questionnaire was completed for controls), level of education (divided into seven categories ranging from no education to university), premorbid body mass index, current alcohol consumption and current smoking. In patients, current alcohol consumption and current smoking were determined at the time of disease onset, so before diagnosis and before the questionnaire was completed.

To determine a difference in the maximum intensity of the activities performed, the maximum MET scores were calculated (excluding duration in years or hours per week) and analysed using the Mann-Whitney U test.

A Cox regression analysis was performed to determine whether survival of patients was associated with physical activity. Survival was defined as the time from symptom onset to death or to the censoring date of 8 August 2011. The HR derived from these analyses were adjusted for gender, age at onset, site of onset and current smoking. Physical activity was entered into the model as a continuous variable. The same method was used to determine the effect of physical activity on the age at onset of ALS patients, adjusting for gender and site of onset. To adjust appropriately for age, an interaction term of diagnosis and physical activity was introduced into the Cox regression analysis using age at the time of completing the questionnaire for controls.

In the above mentioned models, we performed a complete case analysis, using only those cases without any missing values. A Bonferroni correction for multiple testing was applied adjusting for three tests (leisure time, occupational and total activity); a $\mathrm{p}$ value of $0.05 / 3=0.017$ was considered significant.

\section{RESULTS}

In this population based study, $636(84 \%)$ of the 760 patients who gave informed consent to participate in the study between 1 January 2006 and 31 December 2010 returned the questionnaire. Of the 2332 population based controls who gave informed consent, 93\% returned their questionnaires (2166 controls). Table 1 shows the characteristics of the 636 patients and 2166 controls. The patient characteristics of the responders and non-responders were similar. Of the 2802 participants, $2281(81.4 \%)$ had completed the questionnaires on physical activities without any missing values for duration in years or hours per week. The distributions for gender, age at onset and site of onset in ALS patients were similar to those previously reported in population based studies. ${ }^{19}$

A greater amount of leisure time physical activity was associated with an increased risk of ALS in the present study (adjusted OR 1.08, p=0.008) (table 2). This is also illustrated in figure 1 , showing the mean cumulative scores for leisure time activity (patient mean $=1.51,95 \%$ CI 1.30 to 1.72 ; control

Table 2 ORs for the relationship between amyotrophic lateral sclerosis and the cumulative scores of physical activity

\begin{tabular}{|c|c|c|c|c|}
\hline Variable & $\begin{array}{l}\text { Crude OR } \\
(95 \% \mathrm{CI})\end{array}$ & p Value* & $\begin{array}{l}\text { Adjusted OR† } \\
(95 \% \mathrm{Cl})\end{array}$ & p Value* \\
\hline $\begin{array}{l}\text { Leisure time } \\
\text { activity }\end{array}$ & 1.08 (1.02 to 1.13$)$ & 0.005 & $1.08(1.02$ to 1.14$)$ & 0.008 \\
\hline $\begin{array}{l}\text { Occupational } \\
\text { activity }\end{array}$ & 1.02 (0.99 to 1.06$)$ & 0.19 & 1.00 (0.96 to 1.04$)$ & 0.90 \\
\hline Total activity & 1.03 (0.99 to 1.06$)$ & 0.12 & 1.02 (0.98 to 1.06$)$ & 0.30 \\
\hline
\end{tabular}

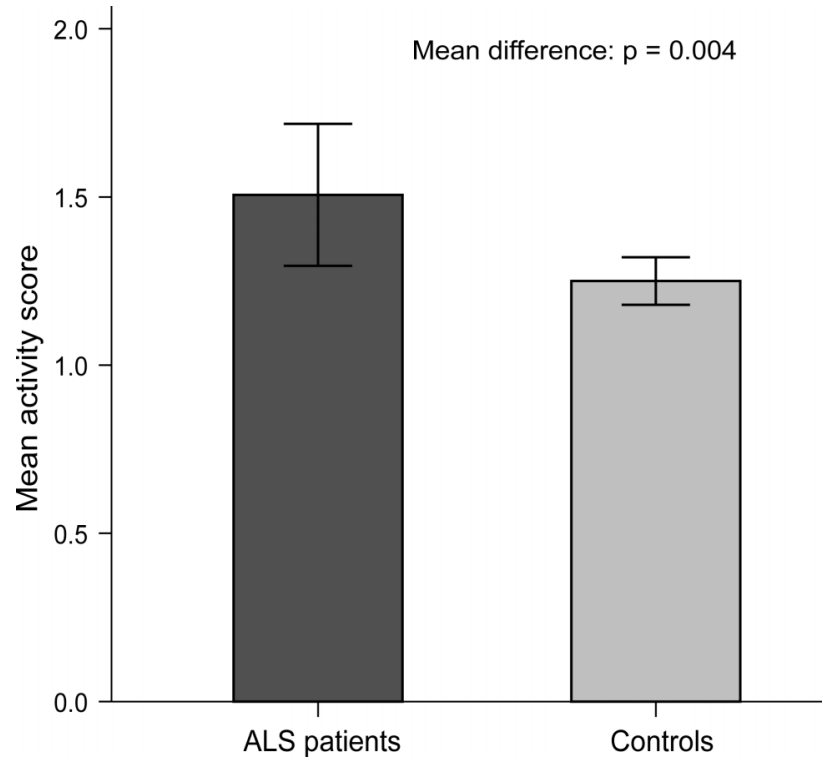

Figure 1 Mean leisure time activity for amyotrophic lateral sclerosis (ALS) patients and controls. Patient mean $=1.51,95 \% \mathrm{Cl} 1.30$ to 1.72; control mean $=1.25,95 \% \mathrm{Cl} 1.18$ to 1.32 .

mean $=1.25,95 \%$ CI 1.18 to $1.32 ; \mathrm{p}=0.004)$. Occupational and total physical activity were not associated with the risk of ALS (table 2); no dose-response relationship was seen with physical activity (figure 2) and none of the vigorous physical activities showed a significant association with ALS (table 3).

Maximum MET scores did not differ significantly between ALS patients and controls, implying that there was no difference in the maximum intensity of activities (all $\mathrm{p}$ values $>0.35$, not shown).

Survival analyses showed that none of the cumulative measures of physical activity was associated with survival (all p values $>0.10$ ). Of 636 patients, $63 \%$ died before the censoring date of 8 August 2011. The cumulative measures of leisure time, occupational and total activity did, however, show a significant relation with age at onset (all HR 0.94-0.95, $\mathrm{p} \leq 0.009$ ). In order to show whether this effect was specific for patients or valid for age at the time of the questionnaire for controls, two additional analyses were performed: (1) an interaction term of

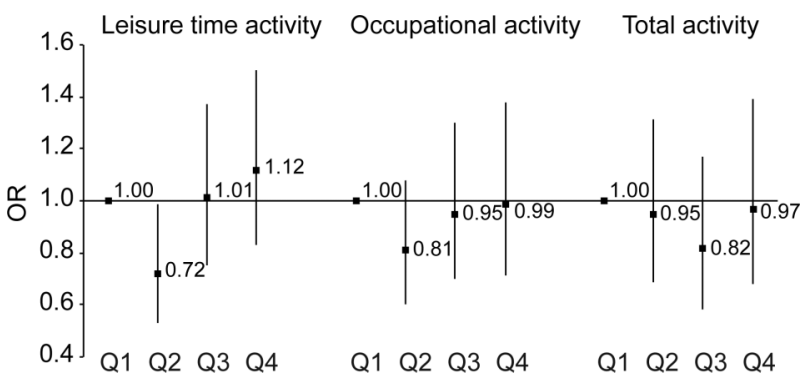

Figure 2 ORs with $95 \%$ Cls for the relationship between quartiles of leisure time, occupational and total activity, and the risk of amyotrophic lateral sclerosis. ORs were adjusted for gender, age at onset, body mass index, current smoking, current alcohol consumption and level of education. The physical activity score was categorised into quartiles (Q) based on the data of controls. Q1, 1st quartile; Q2, 2nd quartile; Q3, 3rd quartile; Q4, 4th quartile. 
Table 3 Vigorous physical activities among amyotrophic lateral sclerosis patients and controls

\begin{tabular}{lccll}
\hline Variable & $\begin{array}{l}\text { ALS patients } \\
(\mathrm{n}=635)\end{array}$ & $\begin{array}{l}\text { Controls } \\
(\mathrm{n}=\mathbf{2 1 6 7 )})\end{array}$ & $\begin{array}{l}\text { Adjusted ORt } \\
(95 \% \mathrm{Cl})\end{array}$ & p Value* \\
\hline $\begin{array}{l}\text { Vigorous } \\
\text { physical activity } \\
\text { (n (\%)) }\end{array}$ & $103(16)$ & $296(14)$ & $1.24(0.96$ to 1.61) & 0.10 \\
$\begin{array}{l}\text { Marathon } \\
\begin{array}{l}\text { Triathlon } \\
\text { Ice skating tours }\end{array}\end{array}$ & $12(1.9)$ & $32(1.5)$ & $1.15(0.58$ to 2.29$)$ & 0.69 \\
$>200 \mathrm{~km}$ & $3(0.5)$ & $6(0.3)$ & $1.21(0.29$ to 4.98$)$ & 0.80 \\
\hline
\end{tabular}

${ }^{*}$ Bonferroni adjusted $\mathrm{p}$ values of $<0.017(0.05 / 3)$ were considered significant.

†Adjusted for gender, age, body mass index, current smoking, current alcohol

consumption and level of education.

ALS, amyotrophic lateral sclerosis.

diagnosis and physical activity was introduced into the model (all $\mathrm{p}$ values $>0.45$ ) and (2) a multivariate Cox regression was performed in controls using questionnaire completion as the event $(\mathrm{p} \leq 0.002)$. Both indicated that the relationship between physical activity and age at onset was an age related effect and thus not disease related. Kaplan-Meier curves of total activity of both survival and age at onset are shown in the online supplementary figure S1.

\section{DISCUSSION}

Evidence for an increased risk of ALS with higher levels of leisure time physical activity is provided by the present population based case control study. Occupational physical activity and performing vigorous physical activities, however, do not appear to modify ALS susceptibility in this study. The discrepancy between leisure time and occupational physical activity strengthens the hypothesis that physical activity itself is not causative per se but that being athletic is a phenotypic expression of a genetic profile, mediated by exogenous factors, that increases the risk of ALS. ${ }^{20-23}$ Our observation that none of the physical activity measures was related to age at onset or survival further supports this hypothesis.

Two systematic reviews on the association between ALS and physical activity concluded that there is a consistent pattern of well designed studies showing no link between physical activity and sporadic ALS. ${ }^{11} 12$ The best evidence available at that time was provided by a single population based case control study that showed no association. ${ }^{24}$ After publication of these reviews, however, a small but well designed European population based pilot case control study identified an increased risk of ALS with higher levels of physical activity. ${ }^{13}$ In concordance with these conflicting results, a third and the most recent systematic review concluded that current evidence for physical activity as a risk factor in motor neuron disease is not of sufficient calibre to allow undisputed conclusions. ${ }^{8}$

The conflicting results found in studies on the association between physical activity and ALS may partly be due to differences in methodological design. These differences concern: (1) the blinding of interviewers to disease status of respondents or the hypotheses being tested; (2) referral bias, which was common with cases often ascertained at specialist clinics; (3) adjustment for confounders, which was not carried out in all analyses; and (4) the method of assessing physical activity, which in most studies was susceptible to recall bias. ${ }^{8} 1112$ Recall bias is due to differential recall of past exposures between patients and controls. As ALS patients actively search for an explanation of their disease or may have an assumption about the underlying cause, case control studies in ALS using questionnaires are prone to this bias. Our study was designed to minimise the risk of recall and referral bias. First, recall bias was reduced by using the Compendium of Physical Activities ${ }^{14}$ to quantify objectively physical activity based on type of occupation or type of leisure time activities, instead of directly asking participants how physically active they have been in their life or during the listed activities. As the questionnaire on leisure time and occupational activities was part of a more comprehensive questionnaire, participants were blinded to the study hypothesis, which further reduced the risk of recall bias. Interviewers, who called participants to complete returned questionnaires, were also unaware of the hypothesis being tested.

Referral bias may occur when patients are ascertained from tertiary care centres. It has been demonstrated that ALS patients attending these referral centres do not represent a random sample of all ALS patients. ${ }^{25} 26$ A difference in physical activity levels of these patients compared with non-referred patients will lead to biased results. The population based design using multiple sources to ensure complete case ascertainment minimised the risk of referral bias in the present study, which was strengthened by the observation that the demographics of the patients in our study resembled those of patients in other population based studies. 192728

We acknowledge certain limitations of the present study: $18.6 \%$ of the participants had at least one missing value for the duration of, or the hours per week spent on, one of the listed activities, even after being called by an interviewer to complete the returned questionnaire. This is probably the result of the level of detail of the questionnaire concerning past events. The fact that this information was so elaborate, however, enabled us to precisely quantify lifetime energy expenditure during leisure time and occupational activities. Also, it is noteworthy that ALS patients had significantly less higher education $(\mathrm{p}<0.02)$, which is congruent with a previous observation that there is a preponderance among ALS patients of blue collar jobs for which a higher level academic education is often not required. Nevertheless, our controls may have been better educated as people with a higher education tend to participate in scientific surveys more readily. ${ }^{29}$ The effects, however, of this observation will have been minimal as we adjusted all analyses for education. Further, we acknowledge that the quantification of the lifetime energy expenditure is still an estimate of real energy expenditure. A study, however, in which these data are prospectively being collected will probably not be feasible in a low incidence disease such as ALS. Finally, although our study was designed to maximise blinding of the participants to the hypothesis of the study, we cannot exclude the fact that a proportion of the patients may have been aware of the theory of physical activity as a possible risk factor, which may have been a source of residual recall bias.

Our finding that an increased leisure time physical activity is related to an increased risk of ALS but occupation activity is not, raises doubts regarding the role of physical activity in causing ALS. Because of existing cellular and genetic evidence supporting the biological plausibility of the association, some have suggested that physical activity is indeed causative. ${ }^{8} 3031$ Several genes associated with the response to exercise (ie, ciliary neurotrophic factor, leukaemia inhibitory factor and vascular endothelial growth factor 2) have been identified as possible modifiers of ALS susceptibility. ${ }^{32-34}$ Also, oxidative stress and glutamate excitotoxicity are considered candidate mechanisms to link ALS and physical activity. ${ }^{78} 35$ The biologically plausible link between physical activity and ALS has been carefully reviewed. ${ }^{8}$ 
Biological plausibility alone, however, does not prove causation. Useful time tested criteria for determining whether an association is causal were designed by Bradford Hill. ${ }^{36} 37$ The Bradford Hill criteria include strength, consistency, specificity, temporality, dose-response relation, plausibility, coherence, experiment and analogy. The associations found in the present study do not meet most of these criteria. First, strength. If an association is weak, it is more plausible that underlying actual causative factors that go hand in hand with the studied factor are in fact responsible for the observed association. In our study, if physical activity were causative, an increase in physical activity of 10000 MET, which can be provided by 50 years of $50 \mathrm{~h}$ cycling per week for example, would be associated with an increase in the odds of developing ALS of only 2.2. Further, if we had applied a more stringent threshold that also corrects for analyses on vigorous physical activities (threshold $p=0.05 / 7=0.007)$, the association $(p=0.008)$ would not even have been significant, further emphasising the weakness of the association. Second, consistency. A real causative factor is more likely to be repeatedly observed in different studies, using different methodologies and performed in different places, circumstances and times. Previous studies, as already emphasised, have shown large inconsistencies, and even within the present study there is an inconsistency between occupational and leisure time physical activity. ${ }^{11-13} 24$ Finally, the absence of a dose-response relation does not support the notion that causation is the most likely interpretation of the association between leisure time physical activity and ALS. Recent findings of a beneficial vascular risk profile in both patients and their relatives, ${ }^{6}$ a reduced frequency of coronary heart disease premorbidly in $\mathrm{ALS}^{22} 38$ and an increased risk of ALS with physical fitness but not muscle strength ${ }^{21}$ further indicate that a common factor underlies both physical/cardiovascular fitness and risk of ALS. ${ }^{39} \mathrm{~A}$ genetic profile, therefore, modified by exogenous factors, that both promotes physical fitness and increases ALS susceptibility, might be a more credible explanation for the associations between physical activity and ALS. ${ }^{20} 22$

In conclusion, the present population based case control study strengthens this hypothesis. Identifying genetic, developmental and environmental factors that contribute to physical fitness may provide a worthwhile lead in unravelling the pathophysiological mechanisms in ALS.

\begin{abstract}
Acknowledgements The authors thank Petra Berk, PhD (University Medical Centre Utrecht), Hermieneke Vergunst (University Medical Centre Utrecht) and Dorien Standaar (Amsterdam Medical Centre) for technical assistance. We thank all neurologists, consultants in rehabilitation medicine and other healthcare providers for enrolling the ALS patients. Finally, we would like to thank all ALS patients and controls for giving their valuable time to participate in this study.
\end{abstract}

Contributors MHBH and MS contributed to the design of the study, acquired the data, introduced data into the database, analysed and interpreted the data, drafted the first version of the article, modified the article by introducing the authors' suggestions and approved the version to be published. SWdJ contributed to the design of the study, acquired the data, introduced data into the database, critically revised the manuscript for important intellectual content and approved the final version to be published. KRISD participated in the analysis and interpretation of the data, critically revised the manuscript for important intellectual content and approved the final version to be published. PTCVD acquired the data, introduced data into the database, critically revised the manuscript for important intellectual content and approved the final version to be published. AJvdK, MdV and HJS contributed to the design of the study, acquired the data, critically revised the manuscript for important intellectual content and approved the final version to be published. LHvdB and JHV originated the idea of the study, obtained funding for the study, contributed to the design of the study, acquired the data, participated in the analysis and interpretation of the data, critically revised the manuscript for important intellectual content and approved the final version to be published.

Funding This work was supported by the Prinses Beatrix Fonds (PB 0703) (Prinses Beatrix Fonds and Kersten Foundation, Postbus 85810, 2508 CM Den Haag,
The Netherlands): VSB fonds (VSB Fonds, Postbus 16, 3500 AA Utrecht, The Netherlands); H Kersten and M Kersten (Kersten Foundation); The Netherlands ALS Foundation (The Netherlands ALS Foundation, Zekeringstraat 42, 1014 BT Amsterdam, The Netherlands); and the JR van Dijk and the Adessium Foundation ( JR van Dijk and the Adessium Foundation, PO Box 76, 2810 AB Reeuwijk, The Netherlands). The research leading to these results has received funding from the European Community's Health Seventh Framework Programme (FP7/2007-2013) (259867) (European Commission, DG Research—Unit F06, CDMA 02/069, B-1049 Brussels, Belgium).

Competing interests $L H v d B$ received travel grants and consultancy fees from Baxter, and serves on the advisory board for Biogen and Cytokinetics. JHV received travel grants from Baxter.

Ethics approval Ethics approval was provided by the institutional review board of the University Medical Centre Utrecht.

Provenance and peer review Not commissioned; externally peer reviewed.

\section{REFERENCES}

1 Kiernan MC, Vucic S, Cheah BC, et al. Amyotrophic lateral sclerosis. Lancet 2011;377:942-55.

2 Lehman EJ, Hein MJ, Baron SL, et al. Neurodegenerative causes of death among retired National Football League players. Neurology 2012;79:1970-4.

3 Chio A, Benzi G, Dossena M, et al. Severely increased risk of amyotrophic lateral sclerosis among Italian professional football players. Brain 2005;128:472-6.

4 Weisskopf MG, O'Reilly EJ, McCullough ML, et al. Prospective study of military service and mortality from ALS. Neurology 2005;64:32-7.

5 Chio A, Calvo A, Dossena M, et al. ALS in Italian professional soccer players: the risk is still present and could be soccer-specific. Amyotroph Lateral Scler 2009:10:205-9.

6 Huisman $\mathrm{MH}$, de Jong SW, Verwijs MC, et al. Family history of neurodegenerative and vascular diseases in ALS: a population-based study. Neurology 2011;77:1363-9.

7 Longstreth WT, Nelson LM, Koepsell TD, et al. Hypotheses to explain the association between vigorous physical activity and amyotrophic lateral sclerosis. Med Hypotheses 1991;34:144-8.

8 Harwood CA, McDermott CJ, Shaw PJ. Physical activity as an exogenous risk factor in motor neuron disease (MND): A review of the evidence. Amyotroph Lateral Scler 2009;10:191-204.

9 Vanacore N, Cocco P, Fadda D, et al. Job strain, hypoxia and risk of amyotrophic lateral sclerosis: Results from a death certificate study. Amyotroph Lateral Scler 2010;11:430-4

10 Armon C. An evidence-based medicine approach to the evaluation of the role of exogenous risk factors in sporadic amyotrophic lateral sclerosis. Neuroepidemiology 2003;22:217-28.

11 Veldink JH, Kalmijn S, Groeneveld GJ, et al. Physical activity and the association with sporadic ALS. Neurology 2005;64:241-5.

12 Armon C. Sports and trauma in amyotrophic lateral sclerosis revisited. J Neuro/ SCi 2007;262:45-53.

13 Beghi E, Logroscino G, Chio A, et al. Amyotrophic lateral sclerosis, physical exercise, trauma and sports: results of a population-based pilot case-control study. Amyotroph Lateral Scler 2010;11:289-92.

14 Ainsworth $B E$, Haskell WL, Whitt MC, et al. Compendium of physical activities: an update of activity codes and MET intensities. Med Sci Sports Exerc 2000;32: S498-504.

15 Brooks BR, Miller RG, Swash M, et al. El Escorial revisited: Revised criteria for the diagnosis of amyotrophic lateral sclerosis. Amyotroph Lateral Scler 2000;1:293-9.

16 Renton A, Majounie E, Waite A, et al. A hexanucleotide repeat expansion in C9ORF72 is the cause of chromosome 9p21-linked ALS-FTD. Neuron 2011;72:257-68.

17 DeJesus-Hernandez M, Mackenzie IR, Boeve BF, et al. Expanded GGGGCC hexanucleotide repeat in noncoding region of C9ORF72 causes chromosome 9p-linked FTD and ALS. Neuron 2011;72:245-56.

18 Ishiura H, Takahashi Y, Mitsui J, et al. C90RF72 repeat expansion in amyotrophic lateral sclerosis in the Kii Peninsula of Japan. Arch Neurol 2012;69:1154-8.

19 Logroscino G, Traynor BJ, Hardiman 0, et al. Incidence of amyotrophic lateral sclerosis in Europe. J Neurol Neurosurg Psychiatry 2010;81:385-90.

20 Scarmeas N, Shih T, Stern $Y$, et al. Premorbid weight, body mass, and varsity athletics in ALS. Neurology 2002;59:773-5.

21 Mattsson P, Lonnstedt I, Nygren I, et al. Physical fitness, but not muscle strength, is a risk factor for death in amyotrophic lateral sclerosis at an early age. J Neurol Neurosurg Psychiatry 2012;83:390-4.

22 Turner MR, Wotton C, Talbot $\mathrm{K}$, et al. Cardiovascular fitness as a risk factor for amyotrophic lateral sclerosis: indirect evidence from record linkage study. J Neurol Neurosurg Psychiatry 2012;83:395-8.

23 Chio A, Mora G. Physical fitness and amyotrophic lateral sclerosis: dangerous liaisons or common genetic pathways? J Neurol Neurosurg Psychiatry 2012:83:389.

\section{(1)}


24 Longstreth WT, McGuire V, Koepsell TD, et al. Risk of amyotrophic lateral sclerosis and history of physical activity: a population-based case-control study. Arch Neurol 1998;55:201-6.

25 Lee JR, Annegers JF, Appel SH. Prognosis of amyotrophic lateral sclerosis and the effect of referral selection. J Neurol Sci 1995;132:207-15.

26 Sorenson EJ, Mandrekar J, Crum B, et al. Effect of referral bias on assessing survival in ALS. Neurology 2007;68:600-2.

27 McGuire V, Longstreth WT Jr, Koepsell TD, et al. Incidence of amyotrophic lateral sclerosis in three counties in western Washington state. Neurology 1996:47:571-3.

28 Forbes RB, Colville S, Parratt J, et al. The incidence of motor nueron disease in Scotland. J Neurol 2007:254:866-9.

29 Galea S, Tracy M. Participation rates in epidemiologic studies. Ann Epidemiol 2007:17:643-53

30 Turner MR, Wicks P, Brownstein CA, et al. Concordance between site of onset and limb dominance in amyotrophic lateral sclerosis. J Neurol Neurosurg Psychiatry 2011;82:853-4.

31 Ferraiuolo L, De Bono JP, Heath PR, et al. Transcriptional response of the neuromuscular system to exercise training and potential implications for ALS. J Neurochem 2009;109:1714-24.
32 Lambrechts D, Storkebaum E, Morimoto M, et al. VEGF is a modifier of amyotrophic lateral sclerosis in mice and humans and protects motoneurons against ischemic death. Nat Genet 2003:34:383-94.

33 Zheng C, Nennesmo I, Fadeel B, et al. Vascular endothelial growth factor prolongs survival in a transgenic mouse model of ALS. Ann Neurol 2004:56:564-7.

34 Al-Chalabi A, Scheffler MD, Smith BN, et al. Ciliary neurotrophic factor genotype does not influence clinical phenotype in amyotrophic lateral sclerosis. Ann Neurol 2003:54:130-4.

35 llieva EV, Ayala V, Jove $\mathrm{M}$, et al. Oxidative and endoplasmic reticulum stress interplay in sporadic amyotrophic lateral sclerosis. Brain 2007;130:3111-23.

36 Hill A Bradford. The environment and disease: association or causation? Proc $R$ Soc Med 1965;58:295-300.

37 Gallo V, Bueno-de-Mesquita HB, Vermeulen R, et al. Smoking and risk for amyotrophic lateral sclerosis: analysis of the EPIC cohort. Ann Neurol 2009;65:378-85.

38 Sutedja NA, van der Schouw YT, Fischer $K$, et al. Beneficial vascular risk profile is associated with amyotrophic lateral sclerosis. J Neurol Neurosurg Psychiatry 2011;82:638-42

39 Wicks P. Hypothesis: Higher prenatal testosterone predisposes ALS patients to improved athletic performance and manual professions. Amyotroph Lateral Scler 2012;13:251-3. 